ReBEn, 35 : 7-16, 1982

\title{
PROBLEMAS PSICOSSÓCIO ESPIRITUAIS DOS CORONARIOPATAS INTERNADOS EM UNIDADES CORONARIANAS
}

\author{
Moema Guedes Barbato* \\ Maria Sumie Koizumi** \\ Edna Marchesotti Engel ***
}

ReBEn/02

BARRATO, M.G. e Colaboradoras - Problemas Psicossócio Espirituais dos Coronariopatas Internados em Unidades Coronarianas. Rev. Bras. Enf.; DF, 35 : 7-16, 1982.

\section{INTRODUÇĀO}

Encontra-se com muita freqüência trabalhos em que se procura identificar, analisar e propor soluçōes para problemas de pacientes internados com patologias específicas como as cardiopatias $^{3}, 8,10,12$.

Especificamenre com pacientes infartados, chama-se muito a atenção sobre os problemas psicossócio espirituais desses pacientes, entretanto pouco ou nenhum trabalho escrito, com dados objetivos a respeito do assunto, é encontrado.

Os fatores psicossociais desempenham um papel tão importante quanto os fatores clássicos de risco na patogê- nese coronariana. O que ainda suscita dúvidas é a natureza da relação entre aqueles fatores e a afecção coronariana. Os coronariopatas caracterizam-se por uma personalidade particular, por um contato freqüente a estresses psicossociais e por dificuldade em superar esses conflitos 4.

O paciente infartado abruptamente percebe sua condiçāo de mortal; ele sabe que se agora não tem dor, sentese melhor, isto não quer dizer que no momento seguinte não surgirá outra crise. Assim sendo, ele deve se adaptar a uma mudança no seu modo de vida ${ }^{13}$.

Torna-se importan'te fazer com que o doente coronariano tome conhecimento do seu modo de ser e possa ter meios

* Docente Livre de Enfermagem Médico-Cirúrgica pela Escola Ana Neri da UFRJ. Professor Assistente da disciplina Enfermagem Médico-Cirúrgica II da EEUSP.

* Mestre em Enfermagem pela EEUSP. Professor Assistente da disciplina Enfermagem Médico-Cirúrgica I da EEUSP.

*** Doutor em Enfermagem pela EEUSP. Professor Assistente Doutor da Disciplina Enfermagem Médico-Cirúrgica II da EEUSP. 
BARRATO, M.G. e Colaboradoras - Problemas Psicossócio Espirituais dos Coronariopatas Internados em Unidades Coronarianas. Rev. Bras. Enf.; DF, 35 : 7-16, 1982.

para enfrentar os problemas que continuarão a existir.

Na rotina diária em UTIs *, utilizadas como campo de ensino às estudantes de Habilitação em Enfermagem Médico-Cirúrgica, procura-se levar os alunos o futuros enfermeiros de campo a planejarem uma assistência de enfermagem individualizada, tendo em vista as necessidades reais dos pacientes em seus aspectos físico, psíquico, social e espiritual.

Com o intuito de fundamentar a identificação dos problemas de pacientes ccronarianos na área física, BARBATO et al. 2 descreveram os principais problemas fisiológicos apresentados por pacientes com infarto do miocárdio e as respectivas prescrições de enfermagem.

Completando os objetivos da disciplina, propôs-se continuar o estudo com pacientes coronarianos agora focalizando as necessidades psicossócio espirituais sentidas e expressadas por estes pacientes.

Os objetivos deste trabalho, portanto, são:

- identificar os principais problemas psicossócio espirituais expressados por coronariopatas internados em unidades coronarianas e ten'tar uma hierarquização dos mesmos;

- detectar as orientações recebidas pelos pacientes coronarianos para a solução de seus problemas psicossócio espirituais;

- propor soluções para os proble. mas psicossócio espirituais apresentados pelos pacientes coronarianos.

\section{METODOLOGIA}

A elaboração deste trabalho baseouse em dados provenientes de uma amos-

\footnotetext{
* UTIs - Unidades de Terapia Intensiva.
}

tra de 28 (vinte e oito) pacientes pesquisados em 3 (três) Unidades Coronarianas pertencentes a hospitais de ensino governamentais, localizadas na capital paulista. Foram escclhidas essas unidades por serem específicas para pacientes coronarianos e em tratamento clínico.

I - População

1. Critérios de seleção

Todos os pacientes internados nas unidades acima referidas, desde que se єnquadrassem nos seguintes critérios:

- coronariopatas, internados em unidades coronarianas por doenças isquêmicas do coração;

- adultos de ambos os sexos;

- pacientes conscientes, em condições de serem entrevistados;

- pacientes internados no mínimo há 48 horas;

2. Características da população estudada

A população, objeto da resquisa, foi de 28 pacientes.

O tempo médio de permanência dos pacientes na UTI *, por ocasião da entrevista, fci de 124 horas.

Em relação ao estado civil, 23 $(82,1 \%)$ eram asados, $4(14,3 \%)$ viúvos e $1(3,6 \%)$ solteiro.

Na tabela I, está apresentada a distribuição dos pacientes segundo sexo e idade. Como podemos observar, a predcminância é do sexo masculino e o grupo etário mais atingido é o de 60 a 75 anos. 
BARRATO, M.G. e Colaboradoras - Problemas Psicossócio Espirituais dos Coronariopatas Internados em Unidades Coronarianas. Rev. Bras. Enf.; DF, 35 : 7-16, 1982.

\section{TABELA 1}

Distribuição dos pacientes segundo sexo e idade, em número e porcentagem. São Paulo, 1981.

\begin{tabular}{c|cccccc}
\hline & \multicolumn{2}{|c}{ Masculino } & \multicolumn{2}{c}{ Feminino } & \multicolumn{2}{c}{ Total } \\
(Em anos) & No & $\%$ & No & $\%$ & No & $\%$ \\
\hline $39 \longmapsto 50$ & 4 & 24,3 & 2 & 7,1 & 6 & 21,4 \\
$50 \longmapsto 60$ & 7 & 25,0 & 1 & 3,6 & 8 & 28,6 \\
$60 \longmapsto 76$ & 10 & 35,7 & 4 & 14,3 & 14 & 50,0 \\
\hline Total & 21 & 75,0 & 7 & 25,0 & 28 & 100,0 \\
\hline
\end{tabular}

Segundo o grau de instrução, 7 pacientes eram analfabetos $(25 \%)$ e 21 $(75 \%)$ alfabetizados. Desses, $10(47,6 \%)$ tinham até a $4 .^{\mathrm{a}}$ série do $1 .^{\circ}$ grau, 8 $(38,1 \%)$ tinham o $1 .^{\circ}$ grau completo e $3(14,3 \%)$ tinham curso superior.

Quanto à nacionalidade, $25(89,3 \%)$ eram brasileiros e $3(10,7 \%)$ estrangeiros.

Em relação à procedência, 16 $(57,1 \%)$ eram da Capital, $7(25 \%)$ do interior do Estado e $5(17,9 \%)$ de outros Estados.

No que diz respeito à experiência de internações anteriores, 21 (75\%) estavam internados pela $1 .^{\text {a }}$ vez em UTI e $7(25 \%)$ tinham experiências anteriores, sendo 5 pacientes com 2 experiências $(71,4 \%)$ e $2(28,6 \%)$ com 3 experiências.

De acordo com a ocupação, 8 $(28,6 \%)$ tinham ocupação especializada, $6(21,4 \%)$ eram aposentados, $5(17,9 \%)$ de prendas domésticas, $4(14,3 \%)$ tinham ocupação não especializada, 3 $(10,7 \%)$ eram autônomos e $2(7,1 \%)$ funcionários públicos.

II - Método

\section{Instrumen'to}

A coleta de dados foi feita pelas autoras do trabalho, mediante um formu- lário específico com perguntas abertas e fechadas (anexo I). Este instrumento foi uma adaptação do formulário utilizado por KAMIYAMA '.

O formulário consta de duas partes distintas.

$\mathrm{Na}$ primeira parte, estão incluídos cs dados de identificação, diagnóstico médico, experiências anteriores de internação em unidades coronarianas e o tempo de permanência por ocasião da entrevista.

A segunda parte é constituída por 6 (seis) perguntas que fundamentam o presente trabalho. A primeira pergunta investiga os problemas psicossócio espirituais sentidos pelos pacientes coronarianos. Da segunda à quinta pergunta, verifica-se a orientação dada a esses problemas e de quem partiu a orientação. A última pergunta esclarece sobre as expectativas desses pacientes para a solução de seus problemas na área psicossócio espiritual.

\section{Aplicação do instrumento}

A entrevista foi feita durante o periodo de 24 de abril a 27 de maio do corrente ano, na própria unidade coronariana e, em um caso, com o paciente na enfermaria já que o mesmo havia tido alta da UTI, mas nela tivesse per- 
BARRATO, M.G. e Colaboradoras - Problemas Psicossócio Espirituais dos Coronariopatas Internados em Unidades Coronarianas. Rev. Bras. Enf.; DF, 35 : 7-16, 1982.

manecido duran'te o intervalo de tempo pré-estabelecido.

Nas três unidades pesquisadas, procurou-se obter autorização da Administração e do Serviço de Enfermagem dos hospitais aos quais elas pertenciam.

Procurou-se entrevistar o paciente em horário onde houvesse menor interferência das visitas médicas, assistência de enfermagem $\theta$ visitas de familiares.

Antes da entrevista, houve o cuidado de verificar com a enfermeira se o paciente estava em condições de ser entrevistado.

O tempo médio de duração da entrevista foi de 24 minutos.

\section{Tratamento dos dados}

Os dados obtidos foram analisados qualitativamente, baseando-se em indices percentuais.

\section{RESULTADOS E COMENTÁRIOS}

No início da entrevista, explicou-se aos pacientes o objetivo da pesquisa, procurando motivá-los e solicitou-se sua colaboração. Todos os pacientes selecionados, segundo os critérios pré-estabelecidos, concordaram em participar e manifestaram um total de 69 (sessenta e nove) problemas.

TABELA 2

Distribuição do número de problemas manifestados pelos pacientes, sagundo a ordem de prioridade. - São Paulo, 1981.

\begin{tabular}{c|ccc}
\hline Prioridade & SIM & NÃO & TOTAL \\
\hline 18 & 27 & 1 & 28 \\
28 & 23 & 5 & 28 \\
32 & 13 & 25 & 28 \\
Outres & 6 & 22 & 28 \\
\hline
\end{tabular}

Como se pode verificar pela Tabela 2, um paciente deixou de informar problemas na primeira prioridade $\mathrm{e}$ se constituiu no único paciente a verbalizar que não teve qualquer problema relacionado com a área psicossócio espiritual.

A proporção de problemas apresentados por paciente foi de 2,5. Foi interessante observar que o número de pro- blemas enunciados pelo paciente foi relativamente alto, desde que se considere que eles foram verbalizados num primeiro e único contato com a pesquisadora, a qual era uma desconhecida para ele.

Por outro lado, como de uma forma geral, não houve diferenças qualitativas quanto ao tipo de problemas mencionados pelos pacientes, sua análise foi feita globalmente. 
BARBATO, M.G. e Colaboradoras - Problemas Psicossócio Espirituais dos Coronariopatas

Internados em Unidades Coronarianas. Rev. Bras. Enf.; DF, 35 : 7-16, 1982.

TABELA 3

Problemas psicossócio espirituais manifestados pelcs pacientes. São Paulo, 1981.

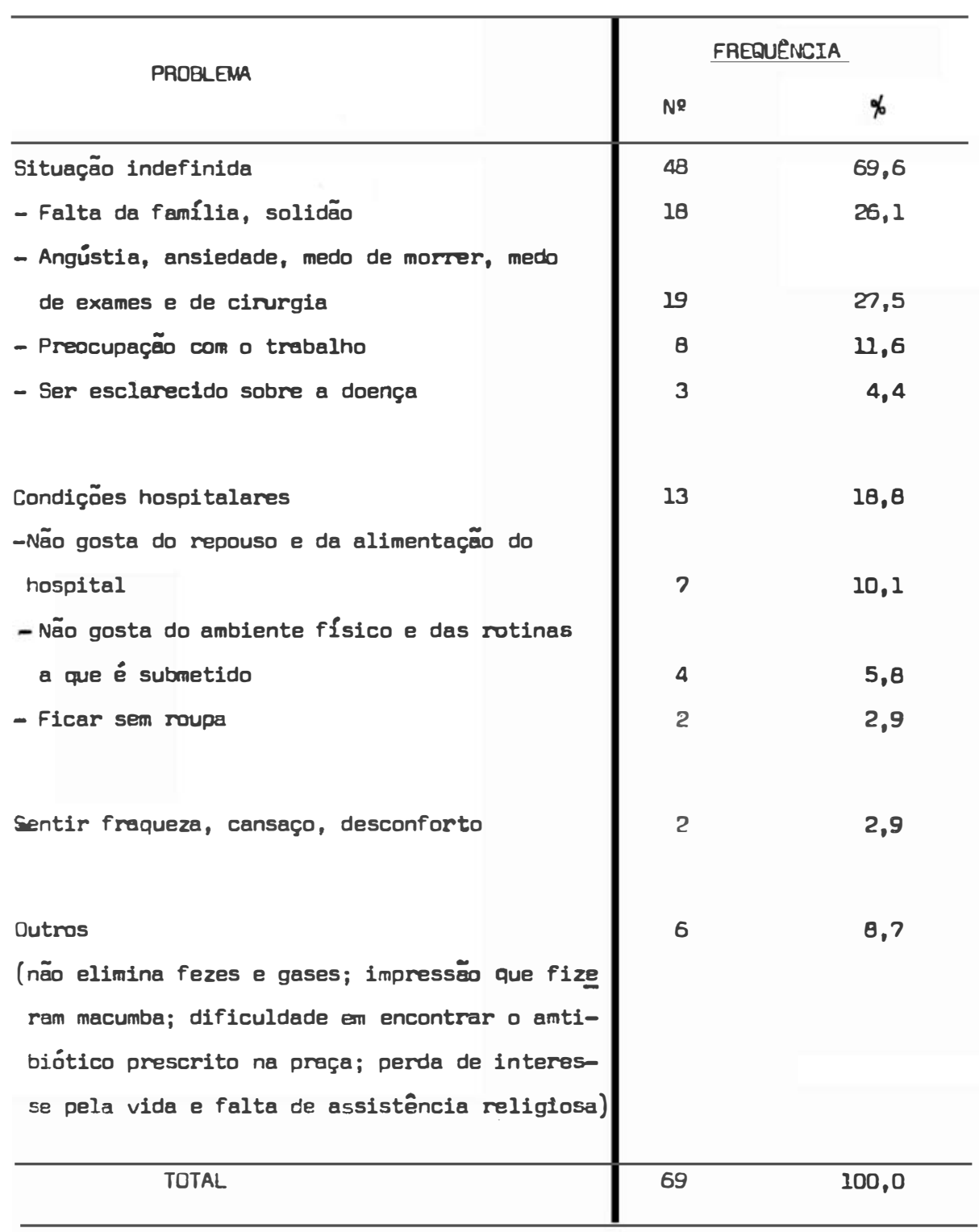

Certamente, considerando a forma como o problema foi verbalizado pelo paciente, pode-se chegar a algumas suposiçōes.
A maioria dos pacientes $(69,6 \%)$ apresentou problemas que refletem uma situação indefinida. Não sabe o que lhe ocorre ou o que lhe ocorrerá e por 
BAREATO, M.G. e Colaboradoras - Problemas Psicossócio Espirituais dos Coronariopatas Internados em Unidades Coronarianas. Rev. Bras. Enf.; DF, 35 : 7-16, 1982.

outro lado teme o que supõe que poderá lhe ocorrer. Nessa situação, seus sentimentos parecem estar ligados à ameaça da morte e aos receios de uma invalidez a longo prazo, receios estes que poucas vezes são mencionados de forma presisa e clara.

Ao mesmo tempo, verificou-se que a grande parte dos pacientes percebiam a unidade coronariana como um elemento tranqüilizador devido à importância da vigilância e da tecnologia que o cerca. Este fato foi observado quando o paciente afirmava "sentir-se seguro dentro da unidade", "que toda hora vem gente ver se está tudo bem" e outras afirmações deste tipo.

Esta observação foi de certo modo surpreendente. E comum observar-se que a insegurança é maior quando a pessoa se encontra em ambiente desconhecido e, principalmente, tenso e agressivo 5, 6, 9, 12 .

Além disso, em uma investigação feita em pacientes adultos submetidos a cirurgia cardíaca e que permaneceram na UTI em média por 58 horas, verificou-se como um dos problemas mais sentidos "o ambiente desconhecido e agressivo" 8 .

De algum modo parece que nas unidades coronarianas os pacientes têm percepções distintas em relação ao ambiente e aos seus próprios receios. Nesse paralelismo, de um lado parece estar o sentir-se seguro porque tem assistência especializada, mas, ao mesmo tempo, há percepção de que não pode distinguir presisamente o limite entre a eficiência do tratamento e a ameaça da morte.

Um outro grupo de problemas destacamos como condições hospitalares. De certa forma o paciente tem hábitos de vida que são quebrados e apesar de saber que são necessários e se submeter a eles, por outro lado, não deixa de sentir falta deles.
Dois pacientes declararam sentir fraqueza, cansaço e desconforto, slassificando-os como problemas da área psicossócio espiritual. Embora não se considere esses problemas como da área em estudo, foram mantidos como expressão do paciente.

Foi interessante observar que os problemas psico espirituais foram pouco verbalizados. Somente um paciente informou sentir falta de assistência religiosa. Julga-se que a ausência de problemas desta área esteja relacionada com o fato de que ministros protestantes e padres visitam rotineiramente as unidades estudadas. Além disso, vários pacientes informaram que buscavam conforto espiritual por meio de oraçōes e leituras que executavam sozinhos.

Conhecer o probema tem importância na medida em que este conhecimento é utilizado para orientar apropriadamente o paciente. Entretanto, nem sempre é fácil ao paciente expor seus problemas para pessoas desconhecidas.

Este fato se torna evidente quando se analisam orientações recebidas e as sugestões dadas pelos pacientes (tabela 4).

Dos 28 pacientes entrevistados, 13 $(46,4 \%)$, informaram ter sido orientados em relação acs seus problemas e $15(53,6 \%)$ não foram orientados, seja por falta de orientação ou porque não verbalizaram seus problemas.

Dos 13 pacientes que foram orientados, verificou-se que 7 orientações $53,8 \%$ ) foram feitas pelo médico, 4 $(30,8 \%)$ pelo médico e enfermeira, 1 $(7, \%)$ pela enfermeira e $1(7,7 \%)$ por outro elemen'to extra-equipe de saúde.

Considerando-se que 7 pacientes foram orientados pelo médico e 4 pelo médico e pela enfermeira, observa-se que dos 13 pacientes orientados, 11 $(84,6 \%)$, receberam orientações dadas pelo médico.

Tem sido observado que nas UTIs, as enfermeiras estão bem informadas 
BARR.ATO, M.G. e Colaboradoras - Problemas Psicossócio Espirituais dos Coronariopatas Internados em Unidades Coronarianas. Rev. Bras. Enf.; DF, 35 : 7-16, 1982.

quanto aos problemas apresentados pelo paciente e, inclusive, informa tê-los orientado. Entretanto, parece que o paciente lembra melhor a orientação feita pelo médico do que a dada pela enfermeira, sendo que estas muitas vezes sequer são lembradas.

Poder-se-ia supor que o paciente quer e espera a orientação médica enquanto que a orientação da enfermeira não se constitui em atividade esperada pelo paciente. $O$ fato da enfermeira orientar parece não repercutir como uma orientação, mas, sim, como um diálogo sem objetivo explícito. Não foi possível distinguir se o paciente sentiu que a enfermeira estava orientando e percebendo seus problemas.

Segundo PAIM 11, ao ouvir o paciente, pelo menos 3 objetivos podem ser alcançados: a) conhecer o principal tema de sua preocupação; b) interpretar o seu tipo de humor diante da narrativa, ou seja, avaliar a importância que ele atribui ao seu próprio problema; c) definir a qualidade da interação estabelecida.

Verificou-se que dos 13 pacientes que receberam orientação, $5(38,5 \%)$ informaram ter sido esclarecidos, 7 $(53,8 \%)$ não se esclareceram e $1 \quad(7,7 \%)$ ficou parcialmente esclarecido.

Muitas vezes o paciente quer tãosomente expressar o que sente, entre- tanto, ouve como resposta orientaçōes padrōes que não respondem a sua ansiedade, pois parece que a resposta está centrada na percepção daquele que responde e não na do indagador. Com muita razão ABDELLAH et al ${ }^{1}$ enfatizam que "se a enfermagem é ajudar o paciente a identificar e resolver seus problemas de saúde, a assistência de enfermagem deve ser centrada nestes problemas" e não determinada pelas necessidades do hospital, pela conveniência da equipe de enfermagem etc.

Perceber realmente o que um paciente deseja saber muitas vezes não pode ocorrer num contato casual. Parece válido conhecer mais, para então, dentro do limite da compreensão do paciente $\theta$ da sua aceitação, passar ao esclarecimento adequado de cada um. Nesse sentido, julga-se que há necessỉdade de um processo de enfermagem, usado como um método adequado para levantamento, análise e interpretação dos dados, a fim de intervir, apropriadamente, dentro das necessidades sentidas pelo paciente, ou seja, colhendo problemas e expectativas do paciente pode-se traçar um seu perfil e dar-lhe respostas objetivas, mas condizentes com sua preocupação real. Essas respostas podem às vezes não ser dadas no momento que ele manifeste seus problemas. O importante é dá-las após termos o seu perfil e assim satisfazer melhor seus anselos.

TABELA 4

Relação entre o paciente ser orientado e oferecer sugestōes. São Paulo, 1981.

\begin{tabular}{|c|c|c|c|c|c|c|}
\hline Orientação & \multicolumn{2}{|c|}{ SIM } & \multicolumn{2}{|c|}{ NĀC } & \multicolumn{2}{|c|}{ TOTAL } \\
\hline Sugestão & № & $\%$ & No & $\%$ & NQ & $\%$ \\
\hline SIM & 6 & 21,4 & 7 & 25,0 & 13 & 46,4 \\
\hline NA๊O & 7 & 25,0 & 8 & 28,6 & 15 & 53,6 \\
\hline TOTAL & 13 & 46,4 & 15 & 53,6 & 28 & 100,0 \\
\hline
\end{tabular}


BARRATO, M.G. e Colaboradoras - Problemas Psicossócio Espirituais dos Coronariopatas Internados em Unidades Coronarianas. Rev. Bras. Enf.; DF, 35 : 7-16, 1982.

Pela tabela 4, verifica-se que parece não haver relação causa-efeito entre orientação e sugestão.

Dos 28 pacientes en'trevistados, 8 $(28,6 \%)$ não foram orientados e não deram nenhuma sugestão. É importante observar que destes, somente um não apresentou problemas.

Observa-se que independentemente de ser orientado ou não, a percepção do problema e a necessidade de resolução não foi atingida na sua totalidade. Isto reforça a hipótese de que há necessidade de investigar cuidadosamente o que o paciente sente e o que realmente ele deseja saber.

Por outro lado, surgem problemas que os próprios pacientes reconhecem não ser a sua solução do âmbito da equipe de saúde.

Das sugestões apresentadas chama a atenção o fato dos pacientes declararem que há necessidade de ser mais esclarecidos, mas ao mesmo tempo não conseguem explicitar como deve ser esse esclarecimento.

As demais sugestões foram diversificadas, não podendo ser analisadas. Salienta-se uma delas onde se observa a diferença de percepção entre o ponto de vista da enfermagem e do paciente. $O$ paciente sugere que no caso de ocorrer um óbito, nunca se colocar um paciente que conhece o fato no mesmo local daquele que faleceu, devido às "fantasias" que podem surgir. Por outro lado, a enfermeira explicando que a mudança é necessária para um melhor controle, aparelhamento mais moderno etc., considera suficiente esta orientação. Isto parece razoável sobre o ponto de vista técnico-cien'tífico, mas não humano.

Embora o problema "falta da familia, solidão" tenha sido o problema mais especificado, não foi apresentada nenhuma sugestão para resolvê-lo. Talvez esse fato esteja ligado à percepção que o paciente tem da impossibilidade de manter um acompanhante na unidade e da aceitação do período de visita como satisfatório. Mesmo na unidade que não permite visita, apesar dos pacientes manifestarem o desejo de "ver os familiares", não apresentaram sugestões. Isto é estranho e só se pode interpretar como uma acomodação às normas e aos regulamentos do hospital.

\section{CONCLUSỎES}

Este trabalho permite chegar a algumas conclusões, embora com a ressalva de que há necessidade de estudos mais aprofundados, aumentando a população e incluindo pacientes de unidades particulares:

- os problemas psicossociais mais freqüentes dos pacientes estão agrupados em: sentir-se em situações indefinidas $(69,6 \%)$ e ter que se adaptar às condições inerentes ao hospital $(18,8 \%)$;

- os problemas psico espirituais não foram manifestados, exceto por um pacien'te;

- do total de pacientes, $46,4 \%$ foram orientados e verificou-se que eles esperam que a orientação seja dada pelo médico;

- dos pacientes orientados, $38,5 \%$ ficaram esclarecidos, $7,7 \%$ parcialmente esclarecidos e $53,8 \%$ não esclarecidos;

- não foi possível a proposição de soluções para os problemas psicossócio espirituais apresentados pelos pacientes coronarianos, pois se verificou ser necessário antes individualizá-lo, traçando seu perfil. 
BAREATO, M.G. e Colaboradoras - Problemas Psicossócio Espirituais dos Coronariopatas Internados em Unidades Coronarianas. Rev. Bras. Enf.; DF, 35 : 7-16, 1982.

\section{B I B L IOG R A F I A}

1. ABDELlaH, F. G. et al - Patient centered approaches to nursing. 3 rd. ed. New York, Macmillan, 1961.

2. BARBAtO, M. G. et al. - Principais problemas fisiológicos apresentados por pacientes com infarto do miocárdio e as respectivas prescriçōes de enfermagem. Rev. Esc. Enf., São Paulo, 13 (2): 147-155, 1979.

3. BAXTER, S. - Psychological problems of intensive care. Nursing Time, 71 (1):22-23, jan., 1975.

4. BLOCH, A. \& BERSIER, A. L. - A psicologia do paciente coronariano. Rev. Geográfica Universal, Doc. Roche 16:83-93, abril, 1981.

5. DICHTER, E. - What patient really wants from the hospital. Mod. Hosp., Chicago, 83:51-54, Sept. 1954.

6. DICHTER, E. - The patient greatest need is security. Mod. Hosp., Chicag. 83:56-8, Oct., 1954.

7. KAMIYAMA, Y. - O doente hospitalizado e sua percepçāo quanto à prioridade de seus problemas. São Paulo, 1972. (Tese de doutoramento - Escola de Enfermagem da USP).
8. KOIZUMI, M. S. et al. - Percepçāo dos pacientes de Unidade de Terapia Intensiva - problemas sentidos e expectativas em relação à assistência de enfermagem. Rev. Esc. Enf. USP., Sā.o Paulo, 13 (2) :135$145,1979$.

9. MASLOW, A. H. - Motivación y personalidad. Barcelona, Sagitário, 1963, pág. 407.

10. PAGLiUCA, L. M. F. - Problemas dos pacientes em pós-operatório de cirurgia cardíaca, na Unidade de $\mathrm{Te}$ rapia Intensiva. São Paulo, 1980. (Dissertaçāo de Mestrado - Escola de Enfermagem da USP).

11. PAIM, L. - Algumas consideraçōes de enfermagem sobre as necessidades psicoss ociais e psicoespirituais dos pacientes. Rev. Bras. Enf.; D.F., 32: 160-166, 1979.

12. REICHLE, M. J. - Psychological stress in the intensive care unit. Nurs. Digest., Wakefield, 3 (3) :12-15, MayJune, 1975

13. ROBERTS, S. L. - Piaget's theory reapplied to the critically ill. $A d v$. Nurs. Sci., New Jersey, 2 (2):61-78, Jan., 1980.

\section{ANEXO I}

\section{FORMULÁRIO PARA ENTREVISTA}

\section{I — IDENTIFICAÇÃO}

Caso n. ${ }^{\circ}$ Unidade

Nome

Idade Sexo Estado Civil

Nacionalidade Naturalidade

Ocupação. Grau de Instrução

Diagnóstico Médico

Data e hora de internação

Experiências anteriores de internação em unidades coronarianas 
BARR.ATO, M.G. e Colaboradoras - Problemas Psicossócio Espirituais dos Coronariopatas Internados em Unidades Coronarianas. Rev. Bras. Enf.; DF, 35 : 7-16, 1982.

Data: ...l $1 \ldots+\ldots$

Início da entrevista:

horas

II - PERGUNTAS

1. O que, além do sofrimento físico (dor, opressão, náuseas, cefaléia), mais incomoda ou incomodou o(a) senhor(a) por estar internado(a) em unidade coronariana? Estabeleça prioridade.

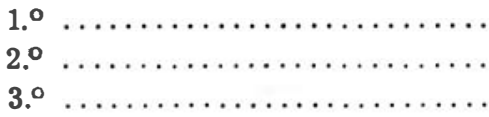

outras
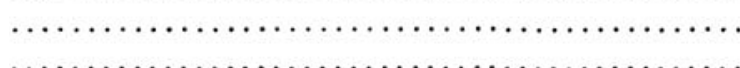

2. Houve alguma orientação sobre os itens acima que o(a) incomodou ou incomodaram?

$$
\text { não }
$$

$\operatorname{sim}$

Caso responder NĀO, passar para a n. ${ }^{\circ} 6$.

3. Quem fez a orientação?

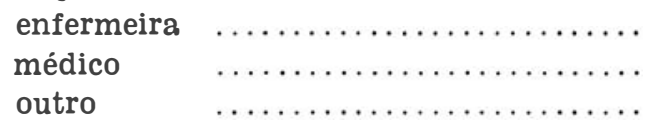

4. Quais os aspectos que foram abordados na orientação?

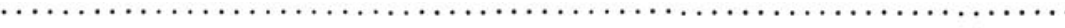

5. A orientação dada foi esclarecedora?

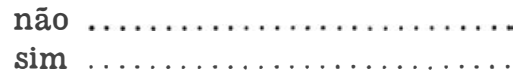

6. Quais as sugestões que o senhor(a) daria para melhorar as preocupações mencionadas na pergunta $n .^{\circ} 1$ ?

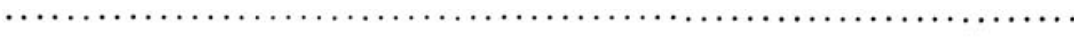

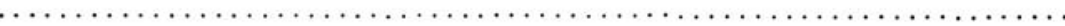

Condições do pacien'te por ocasião da entrevista:

Término da entrevista: horas

Assinatura: 